\title{
DESCASCANDO O ABACAXI CARNAVALESCO DA CHANCHADA: A INVENÇÃO DE UM GÊNERO CINEMATOGRÁFICO NACIONAL
}

\author{
Rafael de Luna Freire ${ }^{1}$
}

\begin{abstract}
Resumo: Compreendo os gêneros cinematográficos como categorias discursivas, este artigo analisa o complexo processo de "generificação" da chanchada que conferiu a um conjunto de filmes anteriormente desprezados $e$ alinhados ao gênero carnavalesco, o estatuto de gênero autenticamente nacional.
\end{abstract}

Palavras-chave: Cinema brasileiro; Gênero cinematográfico; Chanchada.

\begin{abstract}
Comprehending film genres as discursive categories, this article analyses the complex process of "genrification" of the chanchada that gave to a group of musical comedies formerly despised and aligned to the carnival film genre the current and unquestionable status of an authentic national film genre.
\end{abstract}

Key-word: Brazilian cinema; Film genre; Chanchada.

Observando frases presentes em estudos acadêmicos, artigos de jornais, e catálogos de mostras e festivais de cinema, é possível dizer que hoje a chanchada é o principal gênero cinematográfico brasileiro ampla e consensualmente reconhecido como tal por críticos, pesquisadores, jornalistas e também por grande parte do público de cinema brasileiro. Por esse motivo, atualmente a chanchada se constitui inclusive num paradigma de gênero local, sendo freqüientemente utilizado como objeto de comparação no estudo de filmes brasileiros de gêneros supostamente transnacionais (ou tido como "universais"), tais como o horror, o policial ou a ficção científica. Afinal de contas, se Lisa Shaw e Stephanie Dennison (2007, p. 70) intitulam o capítulo de seu livro Brazilian National Cinema sobre esse tema com uma pergunta - "A chanchada, o único gênero brasileiro?" -, a resposta afirmativa vem logo no primeiro parágrafo, quando as autoras confirmam o estatuto da chanchada como "o único gênero verdadeiramente brasileiro" [sem grifo no original]. ${ }^{2}$

Inicialmente um adjetivo pejorativo utilizado para caracterizar filmes considerados "mal-feitos" segundo uma particular concepção de qualidade, este artigo tem como objetivo ilustrar a "generificação" da chanchada, demonstrando como este termo passou entre os anos 1940 e 1960 por um processo de substantivação que, posteriormente, ao longo dos anos 1970 e 1980, o livrou de seu juízo de valor e o habilitou para ser utilizado para descrever de uma

\footnotetext{
${ }^{1}$ Mestre e Doutor em Comunicação pela Universidade Federal Fluminense. Email: rafaeldeluna@ hotmail.com.

${ }^{2}$ Esta e outras citações são traduções livres.
} 
forma mais objetiva (e simplista) o que seria um gênero de comédias - freqüentemente musicais - especificamente nacional.

Este artigo parte de uma teorização prévia acerca dos gêneros cinematográficos (FREIRE, 2011), ressaltando que, tradicionalmente baseada numa análise textual sincrônica, a crítica genérica dedicou-se, em grande parte, a tentar definir o gênero a partir de elementos recorrentes (personagens, temas, cenários, intenções, estruturas narrativas etc.) por meio da análise fílmica. A teoria semântico-sintática dos gêneros desenvolvida por Rick Altman ([1984] 2003) foi um avanço na superação dos arraigados essencialismo e a-historicidade dessas análises, buscando perceber a constante transformação e redefinição dos gêneros. Mais recentemente, porém, frente a uma equivocada concepção de uma suposta universalidade dos gêneros, tem sido colocada em relevo a questão da recepção para sua definição, levando em consideração os variados contextos culturais nos quais os filmes circulam, além dos sentidos diferentes que os termos genéricos adquirem de acordo com seus distintos usuários ou agentes. $^{3}$

Nesse sentido, Jason Mittel $(2001,2004)$ desenvolveu o que chamou de abordagem cultural dos gêneros, não mais centrada exclusivamente em análises textuais, mas defendendo que o historiador do gênero busque "traçar as formas mutantes sob as quais a categoria genérica opera culturalmente" (Ibid., 2004, p. 61), e que tente perceber, nos diferentes contextos históricos, como determinados gêneros foram distintamente identificados, avaliados e definidos.

Conjugando essas molduras teóricas ao estudar o caso da chanchada, buscamos a difícil conciliação entre uma tradicional e recorrente crítica genérica e uma ainda emergente e incipiente (sobretudo no contexto brasileiro) história dos gêneros cinematográficos (cf. ALTMAN, [1984] 2003, p. 29), almejando, como sugere Tom Gunning (1994, p. 4), que teoria e história progridam juntas, com os métodos históricos complementando as conquistas teóricas.

Desse modo, atento à dimensão histórica e cultural dos termos genéricos, é importante apontar que, antes de passar a definir de forma inequívoca um gênero cinematográfico, chanchada era um adjetivo utilizado para caracterizar (negativamente) filmes identificados com vários outros gêneros, como comédias e filmes musicais, revistas ou carnavalescos,

\footnotetext{
${ }^{3}$ Trata-se, portanto, da dimensão pragmática dos gêneros que Rick Altman (1999) adicionou, a posteriori, à sua teoria semântico-sintática. A questão é assim definida por Raphaëlle Moine (2008, p. 11): “categorias genéricas não são as mesmas para qualquer um, em qualquer lugar ou em todas as épocas, porque elas dependem de diferentes relações contextuais com o cinema. Isso significa que elas não podem ter o mesmo significado nem a mesma função em todos os diferentes contextos".
} 
tendo função semelhante a de outros termos pejorativos hoje esquecidos que foram igualmente utilizados nessa função ao longo dos anos, como "borracheira", "pochade" e, principalmente, “abacaxi”. Assim como a fruta é difícil de descascar (ou, pior, de engolir com espinhos e tudo mais), os filmes seriam ruins de serem vistos.

A percepção da existência de um conjunto de filmes brasileiros com traços semelhantes - principalmente, o que era visto como sua constante má qualidade - é perfeitamente capaz de levar a consolidação de um gênero. Afinal, como mostrou Rick Altman (1999, p. 33), "os filmes freqüentemente adquirem identidade genérica por conta de defeitos e fracassos semelhantes, e não somente por qualidades e triunfos compartilhados".

Entretanto, de forma ligeiramente diferente do processo descrito pelo teórico norteamericano, o adjetivo chanchada - que não descrevia um ciclo de filmes, mas qualificava um conjunto de produções (aliás, grande parte da produção nacional) - só veio a se substantivar definitivamente quando passou a abarcar um conjunto específico de filmes, vindo, em seguida, a perder sua carga pejorativa num processo levado a cabo não apenas pela crítica, mas também pela historiografia do cinema brasileiro. Além disso, outras observações podem ser feitas quanto à categorização da chanchada como gênero.

Em primeiro lugar, destacando a freqüente existência de "termos genéricos concorrentes" (FREIRE, 2011), muitos filmes hoje identificados como chanchadas eram divulgados, exibidos e recebidos sob a égide do "carnavalesco". Observando os diferentes significados dos gêneros apontados por Rick Altman (1999, p. 14), podemos afirmar que entre os anos 1930 e 1950 o termo "carnavalesco" se referia simultaneamente a:

1) um modelo: filmes musicais com canções carnavalescas produzidos para serem lançados próximos desta celebração anual, sobretudo nos cinemas do Rio e São Paulo;

2) um contrato aceito pelo público que anualmente já esperava por esse tipo desse filme em certa época do ano;

3) uma estrutura percebida pelos críticos, que os descreviam como "filme carnavalesco", "comédia carnavalesca" ou "revista musical carnavalesca."4

4) uma etiqueta utilizada tanto no anúncio dos filmes, quanto na presença dessa palavra nos próprios títulos - Alô, alô, carnaval (dir. Adhemar Gonzaga, 1936), Carnaval no fogo (dir. Watson Macedo, 1949), Carnaval em Caxias (dir. Paulo Wanderley, 1953), Carnaval em Marte (dir. Watson Macedo, 1954), Carnaval em lá maior (dir. Adhemar

\footnotetext{
${ }^{4}$ Tira a mão daí (dir. Ruy Costa, com pseudônimo, 1956) segundo Tribuna da Imprensa, 7 fev. 1956; Está tudo aí (dir. Mesquitinha, 1939) segundo O Globo, $1^{\circ}$ mar. 1939 (apud GONZAGA, 1987, p. 77); Caídos do céu (dir. Luiz de Barros, 1946) segundo O momento, mar. 1946 (apud GONZAGA, 1987, p 111); Pif-Paf (dir. Luiz de Barros e Adhemar Gonzaga, 1945) segundo Folha Carioca, fev. 1945 (apud GONZAGA, 1987, p. 107).
} 
Gonzaga, 1955), entre outros. Em relação a este aspecto - lembrando ainda que "chanchada", por seu tom pejorativo, jamais funcionou como uma etiqueta genérica - podem ser citadas ainda frases de divulgação de vários outros títulos, como "o maior filme carnavalesco de todos os tempos" (Laranja da China, dir. João de Barro, 1940) ou "o melhor filme de carnaval do ano" (Carnaval Atlântida, dir. José Carlos Burle, 1952), entre outros

O uso isolado da designação "carnavalesco" é um exemplo claro da substantivação - e conseqüente generificação a partir da identificação de uma sintaxe coerente - do que antes seria simplesmente um adjetivo a designar elementos semânticos do carnaval (trilha sonora com sambas e marchinhas carnavalescas, cenários de bailes de carnaval, cenas de desfile de blocos e escolas de samba, personagens de foliões etc.) presentes em diversos filmes de diferentes gêneros, como nos filmes naturais sobre carnaval no período silencioso ou nos primeiros documentários sonoros. ${ }^{5}$

Antes e durante os dias da festa de Momo, quando não apenas estreavam lançamentos que tinham o carnaval como tema, pano de fundo ou trilha musical, mas quando passaram a ser também reprisados filmes de carnavais passados, a identificação pela crítica de diversos elementos em comum (comercialismo, precariedade, rapidez nas filmagens, submissão ao teatro ou rádio etc.) certamente levou à consolidação do carnavalesco como um gênero substantivo a englobar filmes novos e antigos. ${ }^{6}$

Podemos comprovar a nítida percepção da existência do gênero carnavalesco em críticas e resenhas quando se enquadrava Céu azul (dir. Ruy Costa, com pseudônimo, 1941) às expectativas já consolidadas pelos demais filmes do gênero: "o público cinematográfico deve esperar Céu azul como esperou as outras fitas de carnaval"; quando se alinhava Pif-Paf ao que seria o gosto de fãs do gênero: "se quiserem sambas e marchas em quantidade dêem um pulo até o Plaza, na Cinelândia"; quando se reclamava da "genericidade" de Todos por um (dir. Cajado Filho, 1950): "na forma e na essência, todos os filmes carnavalescos são iguais"; quando se elogiava a possibilidade de renovação do gênero ao imaginar que "Carnaval em Caxias será qualquer coisa de carnaval, mas diferente do que costumam ser nossos filmes carnavalescos"; ou, por fim, quando se lamentava a contínua eficácia e popularidade do

\footnotetext{
5 A análise dos gêneros a partir da alternância entre "gêneros adjetivos" e "gêneros substantivos" é um desdobramento proposto por Rick Altman (1999) de sua influente abordagem semântico-sintática dos gêneros.

${ }^{6}$ Informações retiradas de: BARRO, 2007, p. 218; Cinelândia, v. 1, n. 9, fev. 1953, p. 16; Programa do Cinema Pathé, Rio de Janeiro, s.d. [1952] (Acervo Cinemateca do MAM).
} 
gênero apesar da precariedade de Tira a mão daí (dir. Ruy Costa, 1956): "filme carnavalesco é dinheiro em caixa". ${ }^{7}$

Além disso, pela elogiosa resenha de Anatol Rosenfeld ao filme Tudo azul (dir. Moacyr Fenelon, 1951), publicada na revista Íris, podemos perceber, pela exceção, o que seria a regra do gênero para o crítico: "Esta realização de Moacyr Fenelon é um dos mais curiosos filmes de Carnaval já vistos - um filme de Carnaval amargo; amargo e irônico e, contudo, não derrotista. Enfim, um filme de Carnaval inteligente, o que não deixa de uma façanha extraordinária” (ROSENFELD, 2002, p.168).

Se essas "regras" poderiam aparecer também de forma até elogiosa como um gênero que se adequava à precariedade do cinema nacional e cujas fórmulas teriam se desenvolvido para contornar os problemas então irremediáveis da cinematografia local, mais frequentemente, porém, ocorria a reprovação total do gênero, como expresso na resenha a Caídos do céu, que o crítico de O Globo dizia tratar-se de filme de carnaval, "gênero inventado pelo cinema brasileiro, que se baseia na tolice rasgada" (apud GONZAGA, 1987, p. 111). Ainda mais detalhado fora o artigo de Pinheiro Lemos na prestigiada revista Cultura Política, em 1942:

\begin{abstract}
Ninguém discutirá que é nos chamados filmes de Carnaval que o cinema brasileiro atinge o seu nível mais baixo, sob todos os aspectos, da indigência técnica à mais desconsolada falta de imaginação. Em geral, esses filmes se resumem numa reunião mal arrumada de canções, marchas e sambas em voga no momento, ligadas por um fio causal de enredo jocoso e ridículo. Neles nada há que fale à sensibilidade ou à inteligência, na sua negação sistemática e cuidadosa do bom gosto e do bom senso.
\end{abstract}

Entretanto, deixando de lado o "carnavalesco", pretendemos analisar o processo inicial de generificação da chanchada, uma operação discursiva retrospectiva e totalizante efetuada por críticos, cineastas e historiadores que colocou sob a categoria de absoluta precariedade e inépcia até mesmo realizações relativamente ambiciosas para o contexto cinematográfico carioca da época e para a produção tradicional da Atlântida, como Nem Sansão nem Dalila (dir. Carlos Manga, 1954) ou principalmente o maneirista Matar ou correr (dir. Carlos Manga, 1954). Antes da voga da chanchada, a expressão pejorativa mais utilizada em relação às comédias, musicais ou não, carnavalescas ou não, era certamente abacaxi - o público e os

\footnotetext{
${ }^{7}$ Cine-Rádio Jornal, v. 4, n. 133, 23 jan. 1941, p. 3; Folha Carioca, 8 fev. 1945 (apud GONZAGA, 1987, p. 108); Correio Paulistano, 8 fev. 1950 (apud GONZAGA, 1987, p. 151); Cinelândia, v. 2, n. 26, dez. 1953, p. 48-9; Tribuna da Imprensa, 7 fev. 1956.

${ }^{8}$ Cultura Política, v. 2, n. 13, fev. 1942, p. 267.
} 
críticos, coitados, chegavam a se ver obrigados a "ruminar abacaxis 'óleo de rícino' com casca e tudo."9

Tratava-se de um termo utilizado amplamente pelos críticos, mas também pelos espectadores, sendo, portanto, largamente compartilhado. Afinal, entre 1940 e 1942, dezenas de cartas de leitores de Cine-Rádio Jornal endereçadas à sessão "Fala o amigo fan" exibiam títulos como "Em prol do 'abacaxi' nacional” ou "Chega de 'abacaxis'!” Mesmo em 1948, um editorial raivoso de Fred Lee em A Cena Muda adotava o já tradicional título "Chega de abacaxis!...”, enquanto em 1955 Alex Viany publicava no jornal Shopping News uma série de verbetes de personalidades do cinema brasileiro intitulada "Pequena enciclopédia brasileira de filmes, projetos e abacaxis" [sem grifo no original]. ${ }^{10}$

Acima de tudo, "abacaxi" era uma gíria popular e o permaneceu sendo por muito tempo, bastando lembrar do "troféu abacaxi” distribuídos em programas de calouros, como naqueles apresentados por Chacrinha no rádio e posteriormente na televisão.

O começo da mais freqüente utilização da palavra chanchada na avaliação de filmes nacionais provavelmente se deu na passagem para a década de 1940 quando havia uma grande insatisfação com a produção cinematográfica brasileira composta em grande parte de comédias ou revistas carnavalescas estreladas por astros do rádio e do teatro. É sintomático, portanto, que uma das primeiras aparições da palavra chanchada que encontrei foi em reportagem de A Scena Muda sobre os problemas que impediam o desenvolvimento do cinema brasileiro, publicada justamente em 1940 e na qual se comentava que "Luiz de Barros é acusado de só fabricar chanchadas carnavalescas" [grifo do texto]. ${ }^{11}$

Indo mais além, podemos inclusive sugerir que o uso mais recorrente da palavra chanchada no campo da crítica teatral parece ter precedido e, sobretudo, suscitado a utilização do mesmo termo pelos críticos de cinema. Esta é uma hipótese que ainda precisaria ser aprofundada, mas é perceptível que o termo se tornou mais freqüente nas resenhas de filmes quando aumentaram as adaptações para as telas das comédias e revistas teatrais cariocas no final dos anos 1930. A crescente influência (para muitos, perniciosa) do teatro cômico e musical no cinema nacional é evidente na resenha à "cine-revista carnavalesca" Banana da terra (dir. Ruy Costa, 1939) no jornal paulista Folha da Manhã, que apontava que o principal defeito do filme "é devido à influência do teatro carioca de revista: o sentido dúbio dos

\footnotetext{
9 A Scena Muda, v. 20, n. 1019, 1 out. 1940.

10 Pequena enciclopédia brasileira de filmes, projetos e abacaxis. Shopping News, 23 jan. 1955. Disponível em: <www.alexviany.com.br>

${ }^{11}$ A Scena Muda, v. 20, n. 1020,8 out. 1940.
} 
diálogos demasiadamente livres. É preciso que se diga que os responsáveis pela produção não abusaram desse meio fácil de provocar o riso". ${ }^{12}$

Esse alerta persistiria numa crítica ao segundo filme carnavalesco da Sonofilms após Banana da terra, intitulado Laranja da China (dir. Ruy Costa, 1940), que já utilizava o termo chanchada:

Esse é um ponto que deve ser longamente meditado pelos produtores brasileiros, que devem evitar as "chanchadas", próprias para os teatros da Praça Tiradentes, encarando com mais cuidado o grande auxílio que o cinema poderá oferecer à educação do povo. Precisamos fazer filmes mais elevados, com material literário mais apropriado. ${ }^{13}$

No final daquele mesmo ano de 1940, ao reclamar do estado do teatro brasileiro, o escritor Marques Rebelo dizia que o cinema nacional estava no mesmo nível: "Que é que ele tem sido até agora senão a fotografia de más peças teatrais, de 'chanchadas' da Praça Tiradentes?" No mesmo contexto de "fracasso" do cinema nacional, na opinião do crítico Pinheiro Lemos enquanto o cinema brasileiro não se tornasse uma indústria, ele não perderia “este aspecto de 'chanchada' e 'revista' do [Teatro] Recreio." 14

Portanto, discordamos de Rudof Piper (s.d. [1975], p. 18) quando ele assinala que o filme Vamos cantar, dirigido por Léo Marten e lançado no carnaval de 1941, teria sido o marco do "início do definitivo afastamento da crítica em relação à chanchada". Na verdade, trata-se de um quadro mais amplo e complexo que não se resume ao fracasso ou repúdio a um filme em particular (FREIRE, 2011). Havia no início da década de 1940 um contexto maior de crise do cinema brasileiro exemplificado pela indisfarçável revolta expressa por Moacyr Fenelon em uma palestra proferida ao Clube de Fãs Cinematográficos em 1941: "Ficaremos a vida toda alegando que o que dá para fazer de verdade na bilheteria é a chanchada. E o que o público é muito acessível à chanchada. Bom material, bons técnicos, capitalistas, estúdios e artistas - todos trabalhando para um fim só: a chanchada."15

Ainda assim, é preciso ressaltar que na primeira metade dos anos 1940 "chanchada" não era um termo restrito ao universo cinematográfico, mas, pelo contrário, era uma expressão definitivamente multimidiática, assim como "abacaxi”, sendo igualmente utilizada para (des)qualificar peças teatrais e programas radiofônicos.

\footnotetext{
12 Folha da Manhã, 14 fev. 1939, p. 7.

13 Cine-Rádio Jornal, v. 3, n. 78, 18 jan. 1940, p. 15.

${ }^{14}$ Cine-Rádio Jornal, v. 3, n. 125, 28 nov. 1940, p. 5; Diretrizes, v. 4, n. 38, 13 mar. 1941, p. 7.

${ }^{15}$ Cine-Rádio Jornal, v. 5, n. 155, 25 jun. 1941, p. 4.
} 
Por outro lado, Rudolf Piper (s.d. [1975], p. 76) parece ter razão quando afirma que foi apenas no final dos anos 1940 que "se popularizou o termo chanchada, inicialmente destinado apenas aos filmes de péssima qualidade". De fato, uma voga nova - e dessa vez ainda mais intensa - da palavra chanchada na imprensa parece ter se dado somente no pós-guerra e novamente com primazia no noticiário teatral, quando uma parcela da crítica e do meio teatral reclamava por "um gênero de teatro mais sério, pondo de parte a "chanchada", entendida como um gênero "imbecilizado" de "teatro para rir" e quando qualquer peça que resvalasse para a gratuidade, fosse do humor ou da pornografia, era considerada "achanchadada".

Não cabe nos limites deste artigo mapear exaustivamente a utilização do termo chanchada na imprensa diária ou na crítica jornalística brasileira, apenas apontar como a partir do final dos anos 1940 seu uso se tornou cada vez mais freqüente e corriqueiro, embora a análise a menção à chanchada em obras pioneiras do que Arthur Autran (2007) chamou de proto-historiografia e de historiografia clássica do cinema brasileiro dos anos 1950 nos revela algumas surpresas.

Em livros como Romance do gato preto: história breve do cinema, do crítico Carlos Ortiz (s.d. [1953]), ou no livreto de Francisco Silva Nobre, Pequena história do cinema brasileiro (1955), a palavra chanchada, talvez ainda encarada então como gíria, não era utilizada em nenhum momento. Não parece surpresa, portanto, que o mais ambicioso Introdução ao cinema brasileiro, de Alex Viany (1959), marco inicial da historiografia clássica do cinema brasileiro, tampouco se revele muito diferente.

Ao longo do livro, além de chanchada, Viany vai usar ainda as expressões "produções pré-carnavalescas", "musicais carnavalescos" e principalmente seu célebre neologismo "musicarnavalescos", geralmente criticando a produção apressada e desleixada desses filmes e o fato de que o "carnaval mesmo, que é bom, só vem no título", não havendo um retrato verdadeiro da essência e das características dessa festa popular (ibid., p. 107).

Curiosamente, a palavra chanchada só aparece pela primeira vez na página 165 de Introdução ao cinema brasileiro, e ainda em itálico:

Tomemos o exemplo da chanchada. De uns tempos para cá, os produtores verificaram que o filmusical por si só era uma atração de bilheteria, independentemente de compromissos com as músicas de sucesso do carnaval, os cartazes do rádio, ou mesmo os poucos nomes cinematográficos de bilheteria. 
Além de compartilhar a quase completa ausência do termo chanchada em Ortiz (s.d. [1953]) e Nobre (1955), um dado importante de Introdução ao cinema brasileiro (1959) é a sinalização de uma revalorização das produções populares genericamente descritas como chanchadas, ainda que houvesse uma insegurança na utilização do termo e uma indefinição do critério sobre quais filmes pertenceriam a essa categoria. Como escreveu Arthur Autran (2007, p. 23), o livro de Viany marcou o início da historiografia clássica do cinema brasileiro, caracterizada pela idéia de que "a 'maturidade triunfante' do cinema brasileiro ainda irá acontecer, pois a industrialização não se consolidou nem há um núcleo de filmes artisticamente representativos ao nível mundial". Ou seja, a chanchada somente no futuro poderia revelar algum valor.

Essa constatação é fundamental, pois foi provavelmente na passagem para os anos 1960 e ao longo da primeira metade dessa década que o termo chanchada, com seu caráter pejorativo, se substantivou, se consolidou e se popularizou definitivamente no vocabulário cinematográfico, sobretudo em oposição a um novo cinema brasileiro que se anunciava como uma ruptura radical com o passado. Ainda que chanchada permanecesse sendo um adjetivo utilizado para conferir um caráter negativo a todo e qualquer tipo de filme - sendo apropriado com as mais diferentes finalidades e pelas mais diferentes pessoas, fosse um Glauber Rocha ou um Antonio Moniz Vianna, fosse para defender ou atacar o Cinema Novo -, ela passou também a ser largamente utilizada no sentido de um substantivo a englobar genericamente as produções populares, sobretudo comédias e musicais, anteriores ao Cinema Novo. Chanchada passou a representar os filmes ditos vulgares, desonestos e comerciais que representariam até um perigo para um cinema nacional "autêntico", que deveria ser tudo que a chanchada não o era. Como escrevia o próprio Glauber Rocha (1963, p. 12): “a partir de 1962, o que não era chanchada virou "cinema novo"".

Portanto, voltando ao processo de generificação descrito por Rick Altman, inicialmente um adjetivo acrescido a uma variedade de gêneros (comédias, musicais, filmesrevista, filmes caipiras, filmes carnavalescos), pela ênfase em seu significado como fator de diferença (a mediocridade como nos abacaxis, e não mais o carnaval como nos carnavalescos), a chanchada teria se transformado num gênero substantivo, através dos processos básicos descritos por Jason Mittell (2001; 2004) de avaliação, interpretação e definição.

Essa questão anda precisa ser aprofundada em outro contexto, mas é perceptível que chanchada passou a ser largamente utilizada com um substantivo em diversas críticas e artigos publicados na imprensa diária paralelamente ao surgimento do Cinema Novo, assim 
como em textos mais acabados, como pode se notar, por exemplo, em Revisão crítica do cinema brasileiro, de Glauber Rocha (1963), no livro coletivo Cinema Moderno, Cinema Nôvo, organizado por Flávio Moreira da Costa (1966), ou no livreto de David Neves, Cinema Novo no Brasil (1966).

Neste último, o capítulo "Da chanchada ao Cinema Novo" é explícito ao apontar que os "vícios" da chanchada (verbalismo, mediocridade, artificialismo, iluminação "expressionista", rigidez no enquadramento) teriam sido "transportados para os novos temas e gêneros em produção [...] Os defeitos se transferiram da chanchada para outros filmes ditos sérios", chegando a estar presentes em Boca de ouro (dir. Nelson Pereira dos Santos, 1963), obra que seria "uma encruzilhada, um ponto de convergência".

Para usar o vocabulário de Rick Altman, David Neves apontava em 1966 que a semântica da chanchada infestava a sintaxe de outros gêneros, como a tragédia carioca de Nelson Rodrigues produzida e estrelada por Jece Valadão. Por outro lado, ao romper com os elementos típicos do "cinema tradicional ou industrial", um filme como o cinema-novista Porto das caixas (dir. Paulo Cezar Saraceni, 1962), segundo Neves iria contra tudo que vinha antes dele. E esse tudo passava a ser encarado gradativamente por ele e muitos outros sob o guarda-chuva cada vez mais amplo da chanchada.

Alex Viany também utilizou a palavra chanchada em diversos artigos dessa época como os depois reunidos em O processo do cinema novo (1999) -, e também em suas críticas no jornal Shopping News, nas quais empreendeu, ao longo de 1960, a “Operação Chanchada”, clamando os leitores a enviarem críticas sobre os filmes que ele não tinha conseguido assistir: "A operação chanchada só terminará no dia em que o cinema brasileiro tomar vergonha e produzir comédias dignas das tradições de humor do nosso povo."16

Mas ainda que Viany reconhecesse algum valor (mesmo que histórico) no que ele passava a chamar com mais segurança de chanchada, talvez a figura-chave para uma mudança de perspectiva a respeito do cinema popular brasileiro seja Paulo Emílio Salles Gomes (1966, p. 73) que, em seu ensaio Panorama do cinema brasileiro: 1986/1966 escreveu sobre os primeiros anos da Atlântida:

Logo, porém, predominou o gênero chanchada, particularmente após a associação da Atlântida à poderosa cadeia de exibição de Luiz Severiano Ribeiro. Esse encontro entre produção e o comércio exibidor lembra a harmônica e nunca repetida conjuntura econômica que reinou no cinema brasileiro entre 1908 e 1911.

16 Shopping News, Rio de Janeiro, 6 mar. 1960. Disponível em: <www.alexviany.com.br〉. 
Menos interessado nos elementos formais ou temáticos da chanchada (o gênero como estrutura), Paulo Emílio (ibid, p. 74-6) passou a valorizá-la ao entender o "fenômeno" de sua proliferação como um contrato e modelo (nos termos de Rick Altman) que garantiram a mesma "harmonia" entre público, exibidores e produtores que teria ocorrido na bela época do cinema brasileiro. Desse modo, ao invés de ver na chanchada um problema presente ou apenas uma possibilidade futura, Paulo Emílio a definia como o que teria havido "de mais estimulante e vivo no cinema nacional". O início da positivação da chanchada se aliava, portanto, aos primórdios da criação do mito de uma época de ouro do cinema silencioso brasileiro. $^{17}$

Sete anos mais tarde, no clássico ensaio Cinema: trajetória no subdesenvolvimento, já tendo se convertido definitivamente ao cinema nacional, Paulo Emílio iria novamente ressaltar o "fenômeno" da produção de "filmes musicais e de chanchada, ou a combinação de ambos". Aqui ele vai literalmente usar a palavra "acordo" ao falar da relação dos filmes com o público, definindo-o como representativo de um "fato cultural incomparavelmente mais vivo do que o produzido até então pelo contato entre o brasileiro e o produto cultural norteamericano" (GOMES, [1973] 2001, p. 95).

Afirmando que a chanchada, junto com a bela época e o Cinema Novo, foram "os acontecimentos globais de importância na história do nosso cinema" (ibid., p. 99), deve ser ressaltado como as palavras de Paulo Emílio foram fundamentais para revigorar a atenção ao que ele chamou de "fenômeno" das chanchadas - mas que logo passou a ser amplamente compreendido como um gênero - e reforçar o interesse de outros pesquisadores ao longo dos anos 1960 e 1970, notadamente de Jean-Claude Bernardet.

Além disso, deixando de lado as convenções formais que também marcariam esse fenômeno, num momento de ampla discussão a respeito dos caminhos econômicos do cinema brasileiro - quando alguns elementos do Cinema Novo já haviam revisto suas posições iniciais anti-industrialistas remanescentes de debates dos anos 1950, passava a ocorrer o resgate de um heterogêneo grupo de filmes essencialmente lembrados pelo grande sucesso de público e excelentes resultados de bilheteria. Isto é, a partir da revalorização do seu apelo junto às platéias populares - assim como de sua continuidade de produção -, teve lugar a partir do final dos anos 1960 e, sobretudo, ao longo da década seguinte uma "recuperação póstuma do gênero", na expressão de Sérgio Augusto (1989, p. 28), tanto por textos de

\footnotetext{
${ }^{17}$ Sobre o mito da "bela época do cinema brasileiro" e seu questionamento, ver Bernardet (1995) e Souza (2004)
} 
estudiosos e críticos, quanto também através da reapropriação de elementos diretamente associados às chanchadas (certos temas, canções, atores, estúdios e cenários) por filmes de diretores como Joaquim Pedro de Andrade, Rogério Sganzerla, Carlos Diegues e Julio Bressane. Através desse processo, um conjunto amplo e diverso de filmes passou a ser agrupado sob a chancela de chanchada, finalmente utilizado como um "rótulo sem timbre pejorativo" (AUGUSTO, 1989, p. 17).

Obviamente que esse processo não foi simples, nem linear e podemos indicar que essa reavaliação das chanchadas foi vista nos anos 1970 por dois ângulos. Sob um primeiro pontode-vista ela foi encarada - e criticada - como um revisionismo meramente saudosista, nostálgico, populista e nacionalista como o que envolvia o documentário exaltatório Assim era a Atlântida (dir. Carlos Manga, 1975), realizado nos moldes de Era uma vez em Hollywood (That's Entertainment [dir. Jack Haley Jr, 1974]), filme-colagem de cenas de musicais clássicos americanos da MGM divulgado como "mais que um filme, uma celebração".

É nesse sentido de reabilitação da chanchada que podemos incluir diversas reportagens publicadas nos jornais no início dos anos 1970, assim como o livro de Alberto Silva Cinema e humanismo, lançado em 1975 e que incluía o artigo "(re)visão da chanchada", no qual o crítico comentava a então recente revalorização do gênero pelo seu papel histórico de fixar a língua brasileira no cinema e acostumar as platéias com o filme nacional.

$\mathrm{Na}$ mesma direção, ainda que enveredando por um viés mais acentuadamente celebratório, encontra-se o esquecido, mas importante livro de Rudolf Piper, Filmusical brasileiro e chanchada, publicado também em 1975. A primeira frase do livro já dava seu recado: "Na esteira da onda de nostalgia, revalorizou-se, por fim, algo de profundamente brasileiro: a chanchada". Sua argumentação prosseguia ao afirmar que se os americanos e europeus passaram a identificar a década de 1950 como o paraíso perdido, os brasileiros também teriam muito do que sentir saudade: "superficialmente isto aqui era um país maravilhoso há vinte anos atrás. Eram tempos inocentes, de alegria inconseqüente, de liberdade, de esplendor, de muito carnaval, de teatro-rebolado, de luxo, de galãs e... de chanchadas!" (PIPER, s.d. [1975], p. 3-9).

Como os cinema-novistas na década anterior, mas num sentido valorativo oposto, Piper vai utilizar a expressão chanchada como um grande guarda-chuva e, assim, boa parte da história do cinema brasileiro será encarada - e abarcada - a partir desse olhar totalizante. Num contexto marcado pela opressão da ditadura militar, pelo alarmismo voltado à suposta grossura das comédias eróticas, e pelo discurso de luta contra Hollywood pela conquista do 
mercado interno, a chanchada ressurgia como um gênero caracterizado pela alegria, liberdade, ingenuidade e principalmente sucesso popular, mesmo que à custa de comparações completamente arbitrárias.

Independente das críticas específicas ao livro de Piper, é preciso ressaltar que pelo combate ao elitismo ainda muito intenso nos anos 1970 - contexto de continuidade e até intensificação das experimentações de linguagem do cinema moderno e dos cinemas novos -, a mudança de conotação da palavra chanchada pode ser aproximada, em sua devida proporção, de uma atitude eminentemente política de revalorização de filmes populares destinados a platéias populares através de reinterpretações e reavaliações genéricas. Desse modo, a redefinição da chanchada pode ser alinhada ainda a processos semelhantes igualmente retrospectivos que também ocorreram no contexto da década de 1970, como o estabelecimento do gênero queer movie ("filme homossexual") - igualmente se reapropriando de uma expressão anteriormente pejorativa, quando não agressiva - e, sobretudo, do gênero woman's film ("filme feminino"). Num momento de atenção aos processos de recepção e de afirmação de identidades, tanto a chanchada quanto o queer movie e o woman's film vão encontrar seu ponto de unificação último como gênero no fato de se endereçarem ao mesmo tipo de público, respectivamente as igualmente oprimidas platéias populares brasileiras, as platéias homossexuais e as femininas. Assim como ocorreu com os militantes gays e feministas conforme apontou Moine (2008, p. 114), os estudiosos brasileiros da chanchada retiraram do termo toda a conotação negativa e estenderam seu campo de aplicação bem além de seu uso original, incorporando outros filmes anteriormente relacionados a outros gêneros numa nova identidade genérica compartilhada.

Além de sua revalorização a partir de um discurso nacionalista (tanto de cunho populista e nostálgico quanto anti-elitista e progressista), a chanchada também terminou por ser redescoberta pelo discurso hierarquizante político-ideológico. Desse modo, numa influente entrevista concedida em 1974 à revista Cinema - publicada por alunos da Escola de Comunicação e Artes da USP e voluntários da Cinemateca Brasileira - Jean-Claude Bernardet (1974, p. 46) destacaria as chanchadas como filmes "críticos", fazendo a declaração profundamente elogiosa e quase bombástica à época de que a chanchada Nem Sansão nem Dalila era "um dos melhores filmes políticos brasileiros". Entretanto, mesmo diante da objetiva pergunta "O que é chanchada?", Bernardet se esquivou de dar uma resposta definitiva sobre aquilo que vinha sendo encarado com cada vez menos hesitações como um 
gênero, preferindo traçar um quadro ainda mais abrangente para os filmes que a chanchada abarcaria. $^{18}$

Este renovado interesse pelas chanchadas também se relacionava, como assinalou Maria Rita Galvão (In: GALVÃO; BERNARDET, 1983, p. 254), à situação econômica do cinema brasileiro frente aos novos blockbusters hollywoodianos e à passagem das tímidas pornochanchadas para o filme semi-pornográfico, com a definitivamente finada chanchada sendo revista cada vez mais como "um modelo de integração entre o povo e o cinema brasileiro - um 'cinema popular". Diante desse processo de revalorização, um dos maiores símbolos das chanchadas, o diretor Luiz de Barros, foi homenageado e teve um filme e um livro financiados pela Embrafilme na década de 1970. O interesse pela carreira de um veterano "chanchadeiro" como ele era reflexo também da expansão da pesquisa histórica sobre o passado do cinema e pelo crescente interesse das universidades pela história do cinema brasileiro.

Assim, foi também no final dos anos 1970 que surgiram os primeiros trabalhos acadêmicos que tentaram definir, avaliar e interpretar consistente e rigorosamente o que teria sido a chanchada e, entre eles, podemos citar duas dissertação de mestrado, uma de São Paulo e outra do Rio de Janeiro: a de Miguel Wady Chaia, $O$ tostão furado: um estudo sobre a chanchada, defendida na Faculdade de Filosofia, Letras e Ciências Humanas da USP, em 1981, e a de João Luiz Vieira, Foto de cena e chanchada: a eficácia do "star system" no Brasil, da Escola de Comunicação da UFRJ, de 1977, ambas incluindo a palavra "chanchada" em seus títulos ou subtítulos.

Diferentemente do Viany de Introdução ao cinema brasileiro (1959) que via a chanchada como uma identidade posterior à do "musicarnavalesco", e de Paulo Emílio (1966; [1973] 2001) que definiu a chanchada como um fenômeno e como uma modalidade de comédia musical distinta do carnavalesco, na dissertação de João Luiz Vieira (1977) - como na entrevista de Bernardet (1974), no livro de Piper (s.d. [1975]) e em grande parte dos artigos e críticas dos anos 1960 e 1970 -, a chanchada já passava a abarcar o carnavalesco. A partir desse e de outros trabalhos dessa época, se consolidaria definitivamente a dominação discursiva da chanchada frente a outros termos de identificação genérica (film-revista,

\footnotetext{
18 “Acho que chanchada é o nome geral que se dá a todas as comédias, e comédias musicais, de 'apelo' popular, feitas no Brasil entre 1900 e 1960, mais ou menos, em que apareciam astros tipo Oscarito. Mas nunca houve uma definição de chanchada" (BERNARDET, 1974, p. 41). Apesar de sumamente esnobada por outros autores (cf. AUGUSTO, 1989), a resposta de Bernardet parece muito mais astuta, apesar de vaga, do que as dadas por aqueles que se apressaram em conferir uma definição clara e objetiva para o gênero chanchada.
} 
comédia musical, filmusical, carnavalesco, musicarnavalesco etc.), num claro processo de regenerificação.

Ainda nesta dissertação de mestrado e seguindo sugestão de Bernardet, João Luiz Vieira apontou Carnaval no fogo como "o filme clássico das chanchadas", investigando a formação do estrelismo cinematográfico nacional baseado em tipos como o galã, a mocinha, o vilão e o cômico. Era justamente na figura do cômico, como Oscarito e Grande Otelo, que o autor encontrava com mais precisão "os mais diferentes signos de uma latente brasilidade" (VIEIRA, J., 1977, p. 39), enquanto os demais tipos seriam meras importações do estrelismo hollywoodiano:

A "salvação cultural" ficou mesmo por conta de nossos cômicos e do carnaval, a mola mestra da maioria das chanchadas, a forma encontrada para o filme brasileiro se diferenciar do americano. Exatamente no ponto em que eles, os americanos, não poderiam competir conosco (ibid., p. 49).

Ou seja, em meio ao discurso nacionalista da crítica e da historiografia cinematográfica brasileira, a consolidação do gênero (com a definição de um corpus de filmes e a descrição de suas convenções) estaria intimamente associada à afirmação de sua brasilidade, de sua especificidade brasileira, inicialmente expressada através de um humor dotado de crítica social "autenticamente nacional".

Vieira dedicou ainda às chanchadas sua tese de doutorado na Universidade de Nova York - Hegemony and Resistance: Parody and Carnival in Brazilian Cinema (1984) - e publicou dois textos em português que se tornaram referências obrigatórias na bibliografia do gênero: o artigo "Este é meu, é seu, é nosso: introdução à paródia no cinema brasileiro" (VIEIRA, J., 1983) e o capítulo do livro História do Cinema Brasileiro "A chanchada e o cinema carioca (1930-1955)" (VIEIRA, J., 1987).

Ainda nos anos 1980, outros autores também abordaram as chanchadas, como Afrânio Mendes Catani e José Inácio de Melo Souza (1983) no pioneiro livreto A chanchada no cinema brasileiro. Entretanto, outra publicação que se tornou fundamental sobre o assunto e também amplamente responsável pela consolidação da chanchada como gênero foi a pesquisa do jornalista Sérgio Augusto - iniciada ainda no final dos anos 1970, mas somente em 1989 transformada no livro Este mundo é um pandeiro: a chanchada de Getúlio a JK.

De um modo geral, estes trabalhos sobre as chanchadas apresentam diversos problemas comuns à maioria dos estudos genéricos desse tipo, como indefinições de seu escopo, excessivo alargamento das fronteiras ou a restrição a alguns períodos ou diretores 
dentro do gênero, assim como o privilégio a filmes que revelem "consciência política" (Nem Sansão nem Dalila) ou se constituam em "chanchadas reflexivas" (Carnaval Atlântida). Uma característica clara das leituras genéricas clássicas da chanchada é a influência de um modelo biológico evolucionista - típico não apenas da teoria genérica tradicional, como também da própria historiografia clássica do cinema brasileiro -, estabelecendo uma origem distante para o gênero (no cinema silencioso ou nos primórdios do sonoro, geralmente filmes perdidos), que se desenvolve para uma idade de outro (a Atlântida) e, finalmente, para a morte exatamente na mesma época em que "nasce" o Cinema Novo.

Os estudos sobre a chanchada evidenciam ainda contradições inerentes à tentativa de consolidação de um gênero nacional por um viés nacionalista que revela sua clara fragilidade e deixa a impressão de que a chanchada é definida como um gênero legitimamente brasileiro cuja brasilidade é tão óbvia que nem é preciso se dar ao trabalho de explicá-la aos leitores. Desse modo, a conexão da chanchada com a filmografia internacional é outra questão que ainda precisa ser mais bem estudada, tentando repensar e superar, como sugere Moine (2008), uma oposição simplista e redutora entre gêneros locais (como a chanchada) e gêneros transnacionais e trans-culturais (a comédia musical, por exemplo).

Porém, a par de já terem sido apontadas por diversos estudiosos as ligações dos nossos primeiros musicais com exemplares de outras cinematografias - dos filmes de fado portugueses aos filmes de tango argentinos (VIEIRA, 1987, p. 180; COSTA, 2008, p. 126131), sem falar nos musicais hollywoodianos, influência recorrente e principal modelo conforme Sérgio Augusto (1989) -, a distinção da chanchada como um gênero singularmente nacional sobrevive. Talvez isso ocorra por parecer se constituir na única alternativa encontrada para não se falar, como o mesmo Sérgio Augusto (ibid.) não se furta a fazer em seu livro, da chanchada como mera imitação servil do imperialismo cultural norte-americano. Dentre algumas das características invocadas na singularização desse gênero nacional encontra-se a língua brasileira conforme falada e cantada nos filmes ou um tipo particular de humor autodepreciativo (SHAW; DENNISON, 2007, p. 77). Entretanto, um dos argumentos mais fortes continua sendo a influência ou a própria inserção do gênero no universo cultural do carnaval, uma vez que, como aponta Vieira (2000, p. 118), a linguagem carnavalesca sempre permaneceria "como uma espécie de substrato estético e ponto de referência culturalmente codificado".

Por fim, ainda que possam ser feitas justificadas restrições à definição corrente de chanchada como gênero - sobretudo a redução do gênero a um cânone de filmes que geralmente coincide com o caso particular do sistema verticalizado da Atlântida a partir de 
1947 -, fato agravado pela perda de muitos dos filmes que precisariam ser vistos e estudados, não se pretende aqui afirmar ou negar o status de gênero da chanchada. Em nosso caso, o objetivo principal foi analisar como a chanchada foi definitivamente estabelecida como um gênero nacional por críticos e historiadores do cinema através de um processo que não representa um caso isolado e nem especificamente brasileiro.

Como mostrou Altman (1999, p. 72-7), o processo de generificação do "filme feminino" (woman's film) teve início num contexto de ascensão e busca de legitimação da crítica feminista nos estudos de cinema, com o livro pioneiro de Molly Haskell (From Reverence to Rape: The Treatment of Women in the Movies, 1974) e diversos outros que se seguiram na década seguinte, nos quais o gênero ainda era acompanhado de aspas e de hesitação quanto ao seu estatuto genérico. Entretanto, já no livro de Mary Ann Doane de 1987 (The Desire to Desire: The Woman's Film of the 1940s), o gênero finalmente aparecia no título, sem aspas e "sem nenhum resquício de dúvida quanto ao direito da categoria a uma existência independente", seguindo uma tendência já perseguida por outras estudiosas e que seria colocada em prática por virtualmente toda a comunidade crítica.

O caso do filme noir também se presta à comparação, tendo sido uma expressão criada e consolidada por críticos franceses no contexto particular deste país no pós-guerra, mas que só se popularizou nos Estados Unidos e Reino Unido nos anos 1970, ganhando a partir daí ampla circulação (cf. FREIRE, 2011). Ainda que vários autores tenham apontado a incoerência, imprecisão e inconsistência na definição de critérios, na construção de um corpus de filmes e em quase todas as interpretações de sua significação sócio-cultural na forma de gênero, "como resultado da crescente ubiqüidade do termo, e como o resultado da tendência de se produzir filmes baseados em sua imagem, também é argumentado que o filme noir agora tem um status genérico que não possuía no passado" (NEALE, 2000, p. 3 e 174).

Ou seja, da mesma forma que o "filme feminino" ou o filme noir, podemos dizer que a partir do uso reticente e em itálico da palavra chanchada na imprensa dos anos 1940 e posteriormente no livro de Alex Viany (1959), e da difusão de seu uso nos anos 1960 (como desvalorização) e 1970 (para reabilitação), foram estudos consagrados como os de João Luiz Vieira e Sérgio Augusto que consolidaram a regenerificação definitiva da chanchada ao longo dos anos 1980, reinterpretando, redefinindo e reavaliando o gênero e, finalmente, lhe consagrando um status hoje absoluto, positivo e indiscutível não apenas de gênero, mas, sobretudo, de gênero nacional. Obviamente que esse processo só se consumou com o reconhecimento geral e a ampla adoção pela comunidade de críticos, acadêmicos e comentaristas culturais dos limites e fronteiras estabelecidos por esse novo mapa genérico. 
Ao analisarmos os discursos genéricos sobre a chanchada, o objetivo deste artigo não foi chegar a uma inexistente definição correta do gênero (seja o carnavalesco, seja a chanchada), algo indesejável e inviável diante de mapas genéricos que se sobrepõem um após o outro, mas, como sugere Jason Mittell (2001, p. 9, 2004, p. 14), explorar as formas concretas através das quais o gênero foi culturalmente consolidado. Dessa forma, podemos aprender muito não somente sobre a chanchada e sobre a história do cinema brasileiro, mas sobre as formas que a história desse cinema foi construída e reconstruída nas últimas décadas. Os filmes podem permanecer os mesmos, mas os gêneros aos quais eles são identificados ao longo do tempo não são de modo algum estáticos e imutáveis.

\section{Fontes Bibliográficas}

ALTMAN, Rick. [1984] A Semantic/ Syntactic Approach to Film Genre. In: GRANT, Barry Keith (ed.). Film Genre Reader III. Austin: University of Texas Press, 2003.

. Film/Genre. London: British Film Institute, 1999.

AUGUSTO, Sérgio. Esse mundo é um pandeiro: A chanchada de Getúlio a JK. São Paulo: Companhia das Letras: Cinemateca Brasileira, 1989.

AUTRAN, Arthur. Panorama da historiografia do cinema brasileiro. Alceu, PUC, Rio de Janeiro, v. 7, n. 14, jan-jun., 2007.

BARRO, Máximo. 60 anos Atântida. SESC, 2001. Disponível em: <http://www.sescsp.org.br/sesc/hotsites/atlantida>. Acesso em: 20 dez. 2009.

BERNARDET, Jean-Claude. Chanchada. Cinema, Cinemateca Brasileira, São Paulo, n. 3, 1974.

Historiografia clássica do cinema brasileiro. São Paulo: Annablume, 1995.

CATANI, Afrânio Mendes; SOUZA, José Inácio de Melo. A chanchada no cinema brasileiro. São Paulo: Brasiliense, 1983.

COSTA, Fernando Morais da. O som no cinema brasileiro. Rio de Janeiro: 7letras, 2008.

COSTA, Flávio Moreira da (Coord.). Cinema Moderno, Cinema Nôvo. Rio de Janeiro: José Álvaro ed., 1966.

FREIRE, Rafael de Luna. Carnaval, mistério e gangsters: o filme policial no Brasil (19151951). Tese de doutorado - Programa de Pós-Graduação em Comunicação, Universidade Federal Fluminense, Niterói, 2011. 
GALVÃO, Maria Rita; BERNARDET, Jean-Claude. O nacional e o popular na cultura brasileira: Cinema, repercussões em caixa de eco. São Paulo: Brasiliense, 1983.

GOMES, Paulo Emílio Salles. Cinema: trajetória no subdesenvolvimento. 2 ed. Rio de Janeiro: Paz e Terra, 2001.

Panorama do cinema brasileiro: 1986/1966 In: GONZAGA, Adhemar; 70

anos de cinema brasileiro. Rio: Editora Expressão e Cultura, 1966.

GONZAGA, Alice. 50 anos de Cinédia. Rio de Janeiro: Record, 1987.

GUNNING, Tom. D.W. Griffith and the Origins of American Narrative Film: The Early Years at Biograph. Urbana: University of Illinois Press, 1994.

MITTELL, Jason. A Cultural Approach to Television Genre Theory. Cinema Journal, SCMS, v. 40, n. 3, 2001.

. Genre and Television: from Cop Shows to Cartoons in American Culture. New York: Routledge, 2004.

MOINE, Raphaëlle. Cinema Genre. Oxford: Blackwell, 2008.

NAREMORE, James. More than Night: Film Noir in its Context. Berkeley: University of California Press, 1998.

NEALE Steve. Genre and Hollywood. Londres: Routledge, 2000.

NEVES, David. Cinema novo no Brasil. Petrópolis: Vozes, 1966.

NOBRE, Francisco Silva. Pequena história do cinema brasileiro, Cadernos A.A.B.B., Rio de Janeiro, n. 6, 1955.

ORTIZ, Carlos. Romance do gato preto: história breve do cinema. Rio de Janeiro: Casa do Estudante do Brasil, s.d. (1953).

PIPER, Rudolf. Filmusical brasileiro e chanchada. São Paulo: L Oren, s.d. [1975].

ROCHA, Glauber. Revisão crítica do cinema brasileiro. Rio de Janeiro: Civilização Brasileira, 1963.

ROSENFELD, Anatol. Na Cinelândia paulista. São Paulo: Perspectiva, 2002.

SHAW, Lisa; DENNISON, Stephanie. Brazilian National Cinema. Londres: Routledge, 2007.

SILVA, Alberto. Cinema e humanismo. Rio de Janeiro: Pallas, 1975.

SOUZA, José Inácio de Melo. Imagens do Passado: São Paulo e Rio de Janeiro nos primórdios do cinema. São Paulo: Senac, 2004. 
VIANY, Alex. Introdução ao cinema brasileiro. Rio de Janeiro: Instituto Nacional do Livro, 1959.

. O processo do cinema novo. Rio de Janeiro: Aeroplano, 1999.

VIEIRA, João Luiz. A chanchada e o cinema carioca (1930-1955). In: RAMOS, Fernão (Org.). História do cinema brasileiro. São Paulo: Art editora, 1987.

Chanchada. In: RAMOS, Fernão Pessoa; MIRANDA, Luiz Felipe Miranda (Orgs.). Enciclopédia do cinema brasileiro. São Paulo: Senac, 2000.

Este é meu, é seu, é nosso: introdução à paródia no cinema brasileiro. Filme Cultura, Rio de Janeiro, n. 41-42, 1983.

Foto de cena e chanchada: a eficácia do "star system" no Brasil. Dissertação de Mestrado - Escola de Comunicação, Universidade Federal do Rio de Janeiro, Rio de Janeiro, 1977.

\section{Fontes Primárias}

Revistas Cine-Rádio Jornal; Cinelândia; Diretrizes.

\section{Acervos Digitais}

Acervo Folha. Disponível em: < http://acervo.folha.com.br/>

Alex Viany, Disponibilização do Acervo Documental. Disponível em: $<$ http://www.alexviany.com.br/>.

Biblioteca Digital das Artes dos Espetáculos: A Scena Muda e Cinearte, Biblioteca Jenny Klabin Segall, Museu Lasar Segall. Disponível em: <http://www.bjksdigital.museusegall.org.br>.

Centro de Pesquisa e Documentação de História Contemporânea do Brasil - CPDOC, Fundação Getúlio Vargas. Disponível em: <http://cpdoc.fgv.br/>.

Internet Movie Database. Disponível em: 〈www.imdb.com>. 